\title{
Secondary polycythemia
}

INSERM

\section{Source}

INSERM. (1999). Orphanet: an online rare disease and orphan drug data base. Secondary polycythemia. ORPHA:98428

Secondary polycythemia is an elevated absolute red blood cell mass caused by enhanced stimulation of red blood cell production by an otherwise normal erythroid lineage that may be congenital or acquired (congenital secondary polycythemia and acquired secondary polycythemia; see these terms). 